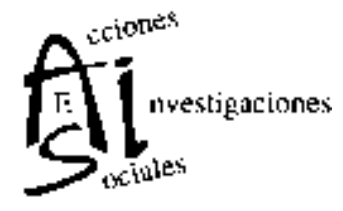

\title{
Salir de la calle: una aproximación etnográfica a un proyecto de revinculación social para personas en situación de la calle en la Ciudad de Buenos Aires
}

\author{
MARIANA BIAGgIO
}

MAGISTER EN ANTROPOLOGÍA SOCIAL BECARIA DOCTORAL DE CONICET UNIVERSIDAD DE BUENOS AIRES marianabiaggio@yahoo.com.ar

Resumen: A partir del análisis etnográfico del proceso de implementación de un proyecto que proponía la conformación de un coro de ensambles vocales de personas en situación de calle, indago en este artículo la ruptura que este proyecto propuso respecto del clásico esquema de asistencia paliativa que caracteriza al circuito asistencial en el que se ubican las políticas sociales dirigidas a la atención de la situación de calle en la Ciudad de Buenos Aires.

Este proyecto, lejos de apuntar a la ayuda material en la supervivencia, otorgó una opción cultural que a partir del placer (no de la necesidad) motivó la participación. Sin embargo, diferentes aspectos oscurecieron este logro imprevisto: desde la mirada de los agentes gubernamentales que lo implementaron, el 
proyecto no logró su objetivo de ser un nexo entre la calle marginal y el mercado laboral formal. Los técnicos asociaban a las personas en situación de calle con una identidad y una localización específica, como si estuvieran desvinculadas de la sociedad. Sin embargo los modos en que las personas vivieron, sintieron y percibieron esta política, nos permiten cuestionar la existencia de aquella desvinculación. Las diversas expectativas en torno al proyecto desnaturalizan miradas y representaciones asociadas a las personas en situación de calle, quienes en esta experiencia se apropiaron de un proyecto del que participaron activamente y defendieron en forma colectiva.

Palabras clave: Situación de calle, Circuitos, Representaciones, Reinserción social y laboral, Técnicos, Beneficiarios, Usuarios.

\title{
Come in off the street: An ethnographic approach to a social reconnection project for individuals living on the streets in the City of Buenos Aires
}

\begin{abstract}
In this paper, taking as my starting point the ethnographic analysis of the process of implementing a project proposing the formation of a choir of vocal ensembles for the homeless, I investigate the break this project brought about with the classic set-up of palliative treatment commonly used by the caring network, embracing the social policies addressing care issues for the homeless in the City of Buenos Aires.

Far from addressing material aid with regard to survival, instead this project offered a cultural option, which encouraged people to take part out of pleasure (rather than out of need). Nevertheless, various aspects contrived to obscure this unexpected outcome: In the eyes of the government agents who brought it into being, the project did not achieve its aim of serving as a bridge between the city's down and outs and the formal labour market. The technicians associated the homeless with a specific location and identity, as if they were cut off from society. However, the ways in which these people lived, felt and perceived this policy enables us to question whether these ties were in fact really severed. The various expectations revolving around the project distort the views and representations associated with the homeless, who, in this experiment, embraced a project in which they played an active part and which they defended as a group.
\end{abstract}

Keywords: Homeless, Networks, Representations, Social and Occupational Reinsertion, Technicians, Beneficiaries, Users. 


\section{Salir de la calle: una aproximación etnográfica a un proyecto de revinculación social para personas en situación de calle en la Ciudad de Buenos Aires}

Recibido: 14-06-2011

Aceptado: 19-11-2011

\section{Introducción}

Entre los meses de agosto a diciembre del año 2008, el Ministerio de Desarrollo Social (MDS) del Gobierno de la Ciudad de Buenos Aires (GCBA) llevó a cabo un proyecto que marcó diversas rupturas en comparación con otras de sus políticas sociales dirigidas a personas clasificadas como "personas en situación de calle". A partir del análisis etnográfico del proceso de implementación del proyecto, nos proponemos dar cuenta de los vínculos entablados entre técnicos y beneficiarios en él involucrados y de las perspectivas y miradas en torno a la representación de la situación de calle.

Fundamentalmente nos interesa detectar cuáles fueron los aspectos que permitieron que las personas en situación de calle se sintieran parte del proyecto, que pudieran apropiarse de él e incluso que lo defendieran colectivamente, alejándose de las prenociones que asocian a las personas en situación de calle con personas aisladas y desvinculadas de la sociedad. La hipótesis que guió este trabajo es que las representaciones en torno a las personas en situación de calle están mediadas por los vínculos conflictivos que se establecen entre técnicos y beneficiarios en el proceso de implementación del proyecto. 
El análisis también permitirá conocer el circuito que realizan las personas en situación de calle que asisten a hogares y paradores, desmitificando algunos prejuicios y representaciones en torno a ellos.

En primer lugar daremos cuenta de los rasgos principales del proyecto, sus diferencias y continuidades con respecto a los demás programas dirigidos a la asistencia de personas en situación de calle, y describiremos la inserción del proyecto en el circuito. Luego analizaremos las posibilidades de participación en él, su conflictivo proceso de implementación y los motivos que llevaron a seguir participando de él, a pesar de todas sus falencias, constituyéndose los beneficiarios en activos participantes que lucharon por su continuidad.

El método etnográfico fue seleccionado en tanto mecanismo privilegiado para acceder a la perspectiva de los propios actores. Para ello, las técnicas utilizadas fueron las entrevistas abiertas y la observación participante que garantizan la exposición directa del investigador a aquella diversidad que aspira aprehender, técnicas que utilizamos desde el inicio del trabajo de campo en el año 2004. Para este trabajo seleccionamos aquellas entrevistas y observaciones realizadas entre los meses de agosto a diciembre de 2008, en el Centro Cultural Plaza Defensa, donde transcurrió el proyecto. El presente constituye un avance del trabajo realizado para mi tesis doctoral orientada al análisis de la clasificación persona en situación de calle y su efecto en la construcción de identidad de las personas así clasificadas. Colocaré en itálicas los términos y dicho nativos, modificando los nombres verdaderos a pedido de los entrevistados, agregando las comillas cuando se trate de una cita textual.

\section{La inserción del proyecto en el circuito}

El proyecto lo implementó el Área de Revinculación Sociocultural y Laboral (ARSL) perteneciente al MDS del GCBA, y propuso la conformación de un coro de ensambles vocales integrado por personas en situación de calle, residentes de hogares y paradores. Los hogares y paradores forman parte del sistema de asistencia de albergues que ofrece el GCBA para la atención de la situación de calle. 
Salir de la calle: una aproximación etnográfica a un proyecto de revinculación $\quad$ AIS - N. ${ }^{\circ} 30(2011) \quad 159$ social para personas en situación de calle en la Ciudad de Buenos Aires

En los hogares las personas en situación de calle pueden residir durante un tiempo prolongado teniendo cada beneficiario una vacante con una duración que -si bien varía de una institución a otra-suele ser de más de tres meses. Los paradores, en cambio, son instituciones que albergan sólo por una noche a las personas que se presentan espontáneamente al lugar. Aquí las vacantes se otorgan por orden de llegada y duran solo una noche, renovándose diariamente. Las personas pueden ir tantas veces como lo dispongan, pero cada vez que asistan, podrán disponer (en caso de encontrar vacante) de una plaza sólo por esa noche. Al día siguiente podrán regresar pero entrarán al parador sólo si hay vacante al momento que se presenten. Por ese motivo, muchas son las personas que deciden hacer una fila en la puerta de los paradores, con el objetivo de reservar, desde temprano, su lugar en el albergue. En ambos casos, las personas ingresan a las instituciones luego de las 17 horas, pudiendo cenar, ducharse y dormir en la institución, debiendo retirarse a la mañana siguiente. Del hogar, salen sabiendo que su vacante estará reservada. Del parador, se van con la incertidumbre en relación a donde pasarán la noche siguiente. $Y$ en ambos casos, se encuentran obligados a pasar la mañana y la tarde en la calle.

Hasta la creación del proyecto del coro, el GCBA contaba con cuatro programas destinados particularmente a las personas en situación de calle: el Programa Hogares, que nuclea a los hogares y propios y conveniados; ${ }^{1}$ Programa Paradores, del cual dependen los tres paradores y el centro de evacuados; el Programa Buenos Aires Presente (BAP) que brinda asistencia en la vía pública por medio de unidades móviles en las que se desplazan los profesionales, hace los traslados que los asistidos necesiten y entrega alimentos y frazadas; el Programa Línea 108, que es un número de teléfono gratuito de emergencia social que recibe llamados y realiza las derivaciones pertinentes a determinados equipos de profesionales del BAP para atender la demanda.

${ }^{1}$ El GCBA tiene tres hogares propios: El Hogar Felix Lora, el Hogar 26 de Julio y el Centro de Noche Costanera. Por medio de convenios con el Ejército de Salvación, Cáritas y la Red SIPAM tiene camas a su disposición en hogares dependientes de estas instituciones (al 2008 tenía convenio con 10 hogares). 
Las personas en situación de calle conocen y utilizan estos programas, además de los ofrecidos desde el ámbito parroquial. Cotidianamente, suelen realizar un recorrido o circuito (como lo llaman las personas en situación de calle y los trabajadores del gobierno) que cuenta con diversas instituciones (públicas y privadas) que brindan desayuno, almuerzo, merienda, cena, duchas, medicamentos y ropa además de los subsidios habitacionales y alimentarios que provee el MDS. Cada oficina, parador, hogar, merendero, comedor, desayunador, ropero comunitario, funciona como un punto del circuito por el que transitan las personas. Marchese (2006) analiza este movimiento constante al que quedan obligadas las personas describiendo un laberinto en el que buscan una salida que más que un lugar es un signo de pregunta. "Recorrer los espacios físicos de las instituciones donde se tramita el acceso a algún beneficio, como un subsidio o ingreso a un hogar, es entrar a un laberinto caótico." (Marchese, 2006). Dado lo difícil que se les hace salir del circuito en el que buscan recursos de primera necesidad, las personas en situación de calle también suelen llamarlo círculo vicioso, aludiendo de esta forma a la relación de dependencia que genera un paliativo sistema de asistencia.

El proyecto del coro no ofrecía comida, ropa ni alojamiento. Realizaba una propuesta cultural, creativa, con una remuneración económica efectiva y una promesa de trabajo futuro. La asistencia a los ensayos que se realizarían dos veces por semana, sería remunerada por una beca mensual de $\$ 245^{2}$. Además, al año siguiente los integrantes del coro tendrían una salida laboral consistente en las presentaciones del coro que serían programadas en las diferentes actividades del Ministerio de Cultura del GCBA, las cuales serían pagas. El proyecto se diferenciaba de los conocidos talleres usualmente asentados en los mismos hogares y paradores, de corta duración y dictados por algún voluntario: esta vez el proyecto se realizaría fuera de

${ }^{2}$ En octubre de 2008 la suma de $\$ 245$ permitía cubrir holgadamente la Canasta Básica de Alimentos, que según el Instituto Nacional de Estadísticas y Censos (INDEC) se encontraba en aquel momento en 143,10\$. Con esa suma de dinero, si bien las personas seguirían estando por debajo de la Línea de Pobreza (representada por la Canasta Básica Total, que se encontraba en aquel momento en 314,96\$) superarían la Línea de Indigencia. Extraído de la página del INDEC, septiembre de 2010. http://www.indec.gov.ar/DEFAULT.HTM 
Salir de la calle: una aproximación etnográfica a un proyecto de revinculación $\quad$ AIS - N. ${ }^{\circ} 30(2011) \quad 161$ social para personas en situación de calle en la Ciudad de Buenos Aires

las instituciones de alojamiento y en un horario distinto al de su funcionamiento. Serían profesores de alto nivel y reconocida trayectoria quienes darían las clases de canto en un proyecto que prometía largo plazo de duración. Manifestaba entonces una clara ruptura con los programas predecesores, particularmente con un clásico esquema de asistencia directa basado en la entrega de recursos materiales y la oferta de instituciones de alojamiento precario y temporario. De alguna manera, se ubicaba por fuera del circuito. Lejos de la espera pasiva a la entrega del recurso, en esta oportunidad, como veremos más adelante, las personas se involucraron en el proyecto y participaron activamente de él, tomando cierto protagonismo en la actividad propuesta.

El protagonismo que el proyecto generó en sus participantes no fue lo único inusual de este proyecto. Además, les ofreció a personas en situación de calle una de las mejores propuestas culturales que el GCBA podría realizar y con continuidad para el año siguiente. Era el director del coro del prestigioso Teatro Colón quien dirigiría el coro de ensambles vocales y tres cantantes de ópera del mismo teatro quienes darían las clases de canto. El espacio donde semejante actividad de características lúdicas, creativas, laborales y de sociabilidad se desarrollaría era el Centro Cultural Plaza Defensa, ubicado en el barrio San Telmo, espacio también transitado y concurrido por personas que no están en situación de calle. Esto contrasta con las actividades que el circuito propone, integradas solamente por personas en situación de calle.

Este proyecto que involucraba a los mejores cantantes de ópera, del teatro más prestigioso de la Ciudad de Buenos Aires prometía también una salida laboral, que fue interpretada por los beneficiarios como la posibilidad de salir de la calle.

El proyecto del coro: las posibilidades de participación de técnicos y beneficiarios

El proyecto estaba coordinado por dos terapistas ocupacionales del ARSL, área que en su nombre describe su objetivo: la Revinculación Sociocultural y Laboral. Esta área depende de la Dirección General de Atención Inmediata (DGDAI) del MDS. De la DGDAI también dependen los demás programas de asisten- 
cia a las personas en situación de calle. Por su parte, el Ministerio de Cultura del GCBA participaba del proyecto aportando los profesores de canto, la dirección del coro, el espacio físico y el marco institucional desde el cual se desarrollarían las actividades del coro, una vez conformado.

El mes de agosto fue destinado a la difusión e inscripción de las personas que quisieran participar. Las personas fueron convocadas por medio de las instituciones donde estaban alojadas: hogares y paradores, tanto para hombres como para mujeres. Aproximadamente cuarenta personas (de las cuales sólo 7 eran mujeres) integraron el grupo de coristas. Si bien les solicitaban, como podía leerse en el tríptico ${ }^{3}$ con el que difundían el proyecto: "compromiso de continuidad de asistencia durante el desarrollo del proyecto", que en la práctica se traducía en un 75 $\%$ de asistencia a los ensayos, el grupo no se mantuvo cerrado. Mientras algunas personas fueron retirándose, otras se integraron pasado ya algún tiempo. Fueron unas 30 personas las que participaron de forma estable desde el inicio del proyecto hasta su finalización.

Fue a partir de la convocatoria que las personas se enteraron de este nuevo proyecto. En su programación no habían sido convocados ni los futuros beneficiarios ni los profesionales que con ellos trabajaban.

"Nos dijeron que nos ocupáramos del aspecto técnico, que le diéramos cierto profesionalismo." Me contaría una de las terapistas ocupacionales en uno de los ensayos, "pero como esto viene de arriba, mucho no podemos hacer." A ellas sólo les pedían que lo ejecutaran y lo enmarcaran en los objetivos de su área: la revinculación social, cultural y laboral de las personas en vulnerabilidad social.

Hasta la creación de este proyecto, las terapistas ocupacionales habían organizado varias tareas para acercarse a ese objetivo, vinculadas con salidas a cines y teatros, una bolsa de trabajo del GCBA y talleres de búsqueda de empleo. En esta oportunidad, las convocaron cuando el proyecto ya había sido anunciado por el director del área y cuando su difusión ya estaba definida y en marcha. Ellas hubieran hecho las cosas de otra forma: principalmente no hubieran anunciado la entrega de una beca ni un posible trabajo al año siguiente.

${ }^{3}$ En el Anexo I puede verse el tríptico entregado para la difusión del proyecto. 
Salir de la calle: una aproximación etnográfica a un proyecto de revinculación $\quad$ AIS - N. ${ }^{\circ} 30(2011) \quad 163$ social para personas en situación de calle en la Ciudad de Buenos Aires

Las terapistas hubieran querido realizar una primera etapa de capacitación hasta que se conformara un grupo sólido y estable de personas con aptitude interés en ser coristas. Y recién en una segunda etapa, durante el año 2009, otorgar a los participantes una remuneración por las diversas presentaciones que se suponía tendría el coro. Para poder enmarcar este proyecto dentro de los objetivos del ARSL, las terapistas sostenían que era imprescindible que las personas en situación de calle participaran de la primera etapa en forma gratuita, sin una contraprestación, sólo por su propio interés. Luego, en una segunda etapa del proyecto, les habrían ofrecido una contraprestación económica que sólo hubiera sido entregada a aquellos que hubieran quedado en el coro, suponiendo que habrían sido personas con interés y aptitud para cantar.

"Yo jamás hubiera dicho desde el principio que había una contraprestación económica. Y menos tratándose de gente que está en la calle. ¿cómo sabemos ahora si están interesados en el proyecto?" Me confiaría una de las terapistas ocupacionales. Y sin el "interés real", las terapistas me explicaban que no confiaban en que tuviera éxito el proyecto, que estaba "viciado de intereses políticos". "Igual te das cuenta de quienes vienen por el subsidio, eso lo notamos, hay gente que ni le importa el coro." El hecho de que la gente fuera por conveniencia, parecía molestarlas mucho. Además "Acá es todo política. No tienen idea de lo que es una actividad terapéutica." Según ellas, las directivas que recibían iban en contra del aspecto terapéutico que ellas querían imprimirle a la actividad, y para lo cual habían sido convocadas. El modo de dar la beca, cómo y cuándo fue anunciada y cómo y cuándo se entregaría, fue la diferencia principal entre las técnicas y los políticos ${ }^{4}$.

${ }^{4}$ Las diferencias notorias entre los "perfiles técnicos" y "políticos", fue analizada por Pantaleón en el caso del Ministerio de Desarrollo Social de la provincia de Salta. Allí destaca que los técnicos "buscan el 'desplazamiento de criterios políticos partidistas' para un buen hacer del desarrollo social” (2004:37). La observación del itinerario ritualizado que hace que un problema social exista, le facilitó al autor el descubrimiento de dos principios de distinción: Uno separa a los que piden en nombre de la necesidad y a los que otorgan en nombre del Estado. El otro principio, interno a los oferentes, es el que diferencia a los segundos por los modos de dar, siendo el principio que une y separa a quienes tienen un perfil técnico de uno político. 
Las terapistas ocupacionales entendieron que el proyecto que les presentaban para ejecutar y al cual debían imprimirle aspectos técnicos que lograran facilitar la reinserción laboral, tenía vicios políticos, obstáculos de origen, por responsabilidad de otros actores, de perfil político, quienes manejaron la información y los recursos acorde a sus intereses y tiempos. A los ojos de las terapistas, ello se reducía a "dar a conocer y hacer visible un proyecto pomposo para ganar prestigio y apoyo político". En ese sentido, incluir desde el inicio de la convocatoria la información acerca de las becas que otorgaría el gobierno, fomentaba la participación de la gente, la asistencia a la actividad propuesta y el apoyo y publicidad del proyecto.

Algunos roces se hicieron sentir cuando las terapistas priorizaban su trabajo técnico desestimando un trabajo de "control" requerido por el director del área, solicitando planillas de asistencia, cuantificando las personas que cada hogar y parador enviaba al coro (evaluando así la "colaboración" de cada institución con el proyecto y con él).

A pesar de estas diferencias entre roles y objetivos correspondientes a cargos políticos y técnicos dentro de la estructura gubernamental, el proyecto logró tener cuatro meses de vida y continuó siendo elegido por sus participantes. La actividad comenzó en septiembre como habían anunciado. A los participantes que cumplieran con los requisitos mencionados más arriba, les entregarían además de la beca, la auspiciada indumentaria oficial artística: polleras, pantalones, zapatos, blusas y camisas; ropa nueva y además hecha a medida. Esta vez no era ropa reciclada, encontrada en la calle, donada por vecinos o entregada en roperos comunitarios. Una de las mujeres me contó que durante esos meses iba a cuidarse en las comidas. Quería adelgazar y verse linda en el "Gran Debut Artístico del Coro", al cual debían asistir en diciembre del 2008, siendo esa la "Gran Presentación de Fin de Año" a la que se comprometían a ir. Una serie de expectativas, compromisos y beneficios giraban en torno al proyecto del coro. Hasta que las becas se hicieran efectivas los participantes tendrían cubiertos los viáticos por medio del uso exclusivo de una camioneta del BAP que los llevaría al centro cultural. Estaban previstas unas demoras en el pago pero la remuneración de las becas sería retroactiva hasta el mes de septiembre, cuando comenzaron los ensayos. 
Salir de la calle: una aproximación etnográfica a un proyecto de revinculación $\quad$ AIS - N. ${ }^{\circ} 30(2011) \quad 165$ social para personas en situación de calle en la Ciudad de Buenos Aires

Con esta información dieron inicio al proyecto del coro, pero no tardaron en sucederse otros inconvenientes imprevistos en su implementación.

\section{Los conflictos en la implementación}

"Estoy cansado de ilusionarme que hay una salida, otra vez pensé que acá la iba a encontrar, y me vuelvo a encontrar con lo mismo. Porque cuando vos llegás a un punto y decís 'cómo salgo?' y creés que la encontrás pero no, y otra vez, pero no... ¿después cómo seguis?" Sergio, integrante del coro.

Hubo quienes habían interpretado, como Sergio, que el coro podía ser una puerta a la salida de la calle, al circuito del comedor, del parador, del hogar. La salida de la calle, fue una expectativa creada por el compromiso que el GCBA había asumido en entregarles una beca y por la promesa (verbal) de la remuneración que obtendrían al año siguiente, con las diversas presentaciones que tendría el coro. Sin embargo, la expectativa de las personas en situación de calle, en torno a la posibilidad de salir de la calle se transformó en una desilusión más. Con el correr del tiempo, el coro no los sacaba de la calle, y al parecer de las técnicas y algunos participantes, el coro parecía mimetizarse y adaptarse cada vez más al circuito ya conocido y transitado por todos los beneficiarios.

Además, hubo problemas durante la experiencia. La camioneta del BAP no cumplió con el acuerdo de llevar y traer a las personas hasta que las becas se hicieran efectivas, y el llegar al Centro Cultural fue un obstáculo muy difícil de sortear para algunas personas. El cobro de la beca que no fue al término del primer mes, ni del segundo, como esperaban, fue otro de los problemas destacados. Por otra parte, después de los primeros ensayos, algunos participantes al llegar a los paradores se encontraron con que ya estaban cubiertos los cupos de las instituciones y esas primeras noches se quedaron en la calle. Si bien esta situación al cabo de unas semanas se revirtió, porque los paradores comenzaron a reservar las vacantes para quienes asistieran al coro, generó mucho malestar. Las promesas incumplidas vinculadas a la entrega de recursos en tiempo y forma renuevan sensaciones de rechazo, de negación y de frustración. 
"No les importa nada. Si verdaderamente creen en la famosa reinserción social ¿por qué no nos dan las becas? Yo agradezco al parador lo que me dan, pero no me alcanza, yo quiero otra cosa para mí. Esto iba a ser una salida laboral, yo iba a poder irme del parador. $Y$ hace un mes que lo único que veo es que lo mínimo establecido no lo cumplen. Si no cumplen con la camioneta (del BAP), mucho menos podemos esperar el trabajo. Es otro fracaso, otra vez una desilusión." Alejandro, integrante del coro.

Para poder cobrar las becas, los requisitos fueron varios, pero el mayor inconveniente fue que esa información fue anunciada unos meses después de comenzada la actividad. Los papeles que debían entregar eran: fotocopia del Documento Nacional de Identidad (DNI), certificación del domicilio en la Ciudad de Buenos Aires con dos años de antigüedad como mínimo y la negativa de la Administración Nacional de la Seguridad Social (ANSES) (esto certifica que el solicitante no cobra ningún beneficio del gobierno, jubilación o pensión, todos los cuales eran incompatibles con la beca).

Esta documentación realiza un recorte aún más específico en torno a la focalización del proyecto en las personas en situación de calle. La selectividad de la "población objetivo", basada en la necesidad de establecer determinados beneficiarios (Grassi, 1994), fue realizada con mayor especificidad: los destinatarios del proyecto fueron entonces las personas que además de estar en situación de calle, contaran con DNI, con residencia comprobable de un mínimo de dos años en la Ciudad y que no recibieran beneficio económico alguno del gobierno.

Hasta que las coordinadoras de la actividad tuvieron la información de que estos eran los requisitos a presentar para poder cobrar la beca, ya habían pasado casi dos meses de comenzado el proyecto. Paralelamente, seguían incorporando gente, a la par que algunos otros desertaban. Tulio, uno de los integrantes del coro, me explicaba que no estaban de acuerdo con la cantidad de papeles que les pedían, en el convencimiento de que eran demasiados exigentes y que muchos de los participantes quedarían fuera. Además, estaban enojados porque les exigieron esos requisitos después de que ellos ya habían hecho el esfuerzo de asistir por casi dos meses a la actividad, trabajo que ahora peligraba de recibir el pago correspondiente. 
Con más de 60 años, Tulio participaba además de otro proyecto del GCBA que también prometía una beca, y que le fue otorgada antes que la beca del coro. Tulio decidió continuar en el coro sabiendo que por esa participación ya no podría cobrar otra beca (los profesionales y encargados de ambos proyectos cuidaban celosamente que no se cruzaran beneficiarios en las bases de datos). Entre los cuarenta participantes del coro, había también otra persona que obtuvo permiso para asistir a pesar de no integrar el grupo que cobraría la beca, de no ser un beneficiario. Se trataba de una persona que vivía en una casa tomada (considerado persona en situación de calle por algunas organizaciones como las del $\mathrm{MOI}^{5}$ o Médicos del Mundo ${ }^{6}$ ), situación que a los ojos del GCBA no la hace una persona en situación de calle (porque no está literalmente en la calle y no asiste a paradores ni a hogares). El hecho de estar incluido en esta otra categoría, la de ocupante, y no en la de persona en situación de calle, le impedía obtener el beneficio de la beca. A los dos los dejaron ir a los ensayos, estando las terapistas convencidas de que eran las únicas dos personas de las que no había duda en que tuvieran un interés real en el canto, demostrado por la asistencia sin posibilidad de cobrar un dinero por ello. Para las terapistas los demás iban sólo por la promesa del dinero.

Argumentando cuestiones de gestión y organizativas, las terapistas explicaron que no podían gestionar una beca por vez, sino que debían hacerlas todas juntas. Esto implicaba tener todos los papeles de todos los participantes y entregarlos todos juntos. Para todos por igual, el cobro sería retroactivo hasta septiembre, mes en que comenzaron los ensayos. Esto implicaba que no se diferenciaría entre quiénes participaron desde el inicio (septiembre) y quiénes desde octubre o noviembre. Con lo cual los "viejos" participantes se sintieron expuestos a una situación injusta respecto con los "nuevos", quienes cobrarían igual que ellos pero habiendo trabajado uno o dos meses menos. Esto empeoró, considerando que también les exigían un $75 \%$ de asistencia a los ensayos para poder cobrar. Si bien esta asis-

\footnotetext{
${ }^{5}$ El Movimiento de Ocupantes e Inquilinos es una organización social que tiene como ejes la vivienda digna, el hábitat popular y el derecho a la ciudad desde principios de la década del ' 90 .

${ }^{6}$ Médicos del Mundo es una organización no gubernamental que trabaja para que el acceso a la salud sea un derecho para todas las personas.
} 
tencia en la práctica no fue un requisito excluyente, funcionó como "amenaza" de que por no cumplir podrían perder la posibilidad de cobrar la beca. A lo largo de la actividad esto generó malestar entre quienes iban desde el principio y quienes comenzaron a asistir tiempo después, así como entre quienes faltaban a los ensayos y quienes no.

Por su parte, las dificultades con los requisitos fueron varios. No todos tenían el DNI (había extranjeros sin documentación argentina) y entre quienes sí lo tenían, no todos lo tenían efectivamente porque muchos lo habían perdido o se lo habían robado. Por otra parte, no todos podían certificar el domicilio en la Ciudad de Buenos Aires. Y finalmente, algunos contaban con pensión, jubilación o algún plan del GCBA, con lo cual resultaban excluidos de cobrar este beneficio. El cobro de la beca peligraba para muchos. Los sentimientos de incertidumbre y la falta de cumplimiento aumentaban el malestar en los coristas, a lo que agregaban como motivo de enojo, el costo económico que implicaba ir a ensayar dos veces por semana ${ }^{7}$.

Otros fueron los problemas desde el punto de vista de las terapistas ocupacionales. El "boca en boca" había generado que la actividad se difundiese en las diversas instituciones del circuito, como merenderos y comedores. Comenzaron entonces a asistir al coro otras personas en situación de calle pero que no asistían a ningún hogar o parador. Para las terapistas una gran dificultad se constituyó en torno a cómo identificar quién era efectivamente una persona en situación de calle. Si el proyecto estaba destinado a este grupo de personas ellas debían garantizar que sólo a ellas llegaría la actividad, y por eso la convocatoria se había realizado solamente en los hogares y paradores. Para salvar estas dudas, comenzaron a requerir un certificado que constatara tal condición, que se sumó a los papeles requeridos para el cobro de la beca.

Este tema del cobro de la beca en concepto de viáticos, tomó tanta importancia que la actividad lúdica, artística, creativa y el futuro laboral comenzaron a quedar empañados por los problemas económicos y de gestión institucional. Las terapistas

${ }^{7}$ Entre los gastos ocasionados mencionaban el viaje (debido a la falta de la camioneta del BAP) y el almuerzo (la asistencia a comedores se dificultaba por la lejanía entre el centro cultural y esas instituciones). 
Salir de la calle: una aproximación etnográfica a un proyecto de revinculación $\quad$ AIS - N. ${ }^{\circ} 30(2011) \quad 169$ social para personas en situación de calle en la Ciudad de Buenos Aires

comenzaron a percibir que su trabajo se veía frustrado, que los objetivos de reinserción social y laboral no se cumplían. Estaban convencidas que los beneficiarios iban al coro para tener la vacante asegurada en el parador y para cobrar la beca. La actividad creativa y el futuro laboral eran percibidos como objetivos perdidos. Lejos de ser un nexo entre la situación de calle marginal y la inserción en la sociedad y en el mercado laboral formal, el coro se estaba convirtiendo a los ojos de las terapistas, en uno de los tantos marginales espacios de personas en situación de calle, al que les costaba ver un futuro diferente. El coro comenzaba a ser visto como un punto más del circuito que realizan las personas en situación de calle en la búsqueda de recursos para sobrellevar el día a día.

Sintiéndose molestas por su convencimiento de que las personas querían ir al coro por el único interés en la beca, las terapistas se pusieron más exigentes con el cumplimiento del requisito de asistir al $75 \%$ de los ensayos y de ser una "persona en situación de calle", queriendo cerciorarse del lugar de residencia y comprobar si efectivamente estaban en el parador donde decían. No sólo esa tarea no era necesaria que la hicieran, sino que iba a verse a todas luces frustrada. "¿Pero vos vivís en el Bepo?"8 Era una de las preguntas de las terapistas. Aludían así, a cierta estabilidad residencial que no se ajustaba a la dinámica de la vida de las personas en situación de calle, que no "son del Bepo" o "de Retiro", de hecho, no son ni están en un solo parador. Si bien es cierto que suelen ir con frecuencia y cotidianamente a un mismo lugar (y no intercambiar lugares) la dinámica de cambio de paradores y hogares donde se alojan y de interrupción en la concurrencia a una misma institución es lo más frecuente: sea por dificultades en la convivencia con otros usuarios, por egresos ${ }^{9}$ de las instituciones, por detenciones policiales, por internaciones en hospitales, porque consiguieron la posibilidad de pagar una habitación, porque un amigo los alojó unos días, entre otros de los tantos motivos de una vida que se vive en el día a día.

\footnotetext{
8 "Bepo Ghezzi" es el nombre de uno de los paradores para hombres adultos. El otro es el "Parador Retiro". El parador de mujeres se llama "Azucena Villaflor".

${ }^{9}$ El egreso es el eufemismo que utilizan las autoridades de los paradores para llamar a las expulsiones, sean permanentes o temporales.
} 


\section{Y entonces ¿por qué seguir asistiendo?}

Los ensayos duraron cuatro meses: septiembre a diciembre de 2008. Para asistir cada uno resolvió como pudo la forma de viajar, utilizando un pase de transporte para personas con discapacidad falso, pagando el boleto, caminando o en bicicleta.

A pesar de los problemas organizativos y de la falta de cumplimiento en lo prometido, muchos decidieron seguir asistiendo hasta el final. Tulio estaba muy contento con la actividad, en sus palabras: "la parte técnica es muy buena, los profesores son encantadores. Me siento muy bien en este lugar".

En esa actividad (si bien después de algunas semanas con inconvenientes) lograron evitar el hacer la fila para ingresar a los paradore ${ }^{10}$, teniendo los días de los ensayos la cama reservada en el parador donde solían alojarse. Los beneficios adicionales que otorgaba la asistencia al coro, según la percepción de quienes asistían a paradores, fueron así expresadas: "En realidad yo prefiero venir acá antes que estar en la fila. En la fila no me aguanto a la gente, te soy sincero, se quejan todo el tiempo. No tengo ganas de escuchar los problemas de los demás." Tulio me dijo que si yo prestaba atención, iba a darme cuenta de que en el centro cultural donde ensayaban la gente estaba hablando de música, de los profesores que eran muy divertidos, de cómo estaban progresando o del debut del coro. En contraste diferencia, en la fila del parador la gente solía quejarse y hablar de sus problemas. En el coro la gente no se quejaba tanto. Sí discutían las dificultades de la camioneta que no los pasaba a buscar, la beca que no les pagaban y otros temas difíciles pero la pasaban bien.

Por otra parte, cabe señalar algunas diferencias entre ambos espacios. En el centro cultural (al cual acudían desde dos o tres horas antes de los ensayos, no por necesidad de hacer fila, sino porque les gustaba estar ahí) había baños, acceso a un dispenser con agua fría y caliente, un gran patio con mesas con tableros de ajedrez, bancos y sillas, árboles que daban sombra y dejaban a la distancia los ruidos de la calle ${ }^{11}$.

\footnotetext{
${ }^{10}$ La fila que realizan para aumentar las posibilidades de ingreso a los paradores, suele ser desde varias horas antes de su apertura, lo que genera mucho malestar. La reserva de camas para los participantes del proyecto del coro, les evitó durante esos meses, la necesidad de estar allí y les brindó un descanso de esa situación.

${ }^{11}$ En el Anexo II pueden verse algunas fotos del Centro Cultural.
} 
Salir de la calle: una aproximación etnográfica a un proyecto de revinculación $\quad$ AIS - N. ${ }^{\circ} 30(2011) \quad 171$ social para personas en situación de calle en la Ciudad de Buenos Aires

También había un espacio bajo techo, con sillones, y una galería donde siempre había alguna muestra de arte. La fila del parador, en cambio, debían realizarla en la vereda, sin techo cercano, al rayo del sol o expuestos a posibles lluvias. Mientras estaban en la fila seguían en la calle, estando aún el parador cerrado, lo que restringía aún más las posibilidades de acceso al baño y al agua, dependiendo para ello del permiso de alguna estación de servicio o bares de la zona, separados por varias cuadras de distancia.

El hecho de evitar el hacer la fila en el parador, el bienestar de un patio fresco y un centro cultural cálido, las charlas amenas, el placer del canto y de los ejercicios de relajación, el disfrute de profesores respetuosos con muy buen humor, sumada a la posibilidad de "matar el tiempo" haciendo algo divertido, fueron los diferentes motivos que señalaron las personas a la hora de justificar el hecho de "todavía estar ahí" a pesar de las dificultades y del maltrato institucional del GCBA que no cumplía con lo prometido.

Estos aspectos nos están informando acerca de un gusto y una elección de las personas que participaron del coro. Asistieron a un lugar porque les gustaba; y ese gusto estaba asociado a un centro cultural, a los vínculos humanos y a una propuesta creativa y artística.

Al contrario de lo que creían las terapistas, esa elección fue realizada sin la existencia de una contraprestación económica: un grupo de 30 personas asistió desde el inicio y hasta el final de la actividad sin cobrar, puesto que las becas se hicieron efectivas recién a mediados de diciembre, casi cuatro meses después de iniciados los ensayos. La asistencia al coro siguió siendo una opción válida e interesante, a pesar de la falta del cobro y de los problemas organizativos. El placer del canto, el trato respetuoso y la calidez del lugar fueron suficientes motores para concurrir a la actividad.

El trato respetuoso de los profesores, estaba acompañado de un contacto expresivo y corporal con los participantes que contrastaba tanto con el distante saludo recibido por los trabajadores insertos en instituciones del circuito, como con el trato frío de los médicos y enfermeros que mediatizan el contacto con guantes de látex. Para corregir la salida del aire, incentivando a que lo hicieran desde la panza y no desde la garganta, los pro- 
fesores acariciaban las caras, relajaban el gesto, la espalda y los hombros, aliviando tensiones innecesarias. De esta manera, enseñaban a respirar, a relajar el pecho, a permitir que el aire fluya hasta el diafragma, a proyectar la voz, a cantar. Para eso, los profesores insistían en el cuidado de la postura corporal: el cuerpo debía estar firme, erguido, pero no rígido. Relajado, pero no por eso abandonado. A diferencia del circuito -donde el cuerpo conocido y esperado era un cuerpo dolido, golpeado, "merecedor" de asistencia- la expectativa en el coro era la de cuerpos sanos, fuertes, de erguidas posturas, que pudieran lucirse, mostrarse y para lo cual entregarían indumentaria oficial artística. En cuanto a las voces, en el coro no las había ni buenas ni malas: cada uno debía descubrir cuál era la suya (para lo cual debía en principio animarse a escuchar su propia voz) y una vez descubierta, jugar con ella y explorarla para proyectarla. Al cabo de algunos ensayos, el coro ya sonaba como un coro, era grato escucharlo y comenzaron a seleccionar algunas canciones para trabajar y poder presentar en el debut artístico, "La Gran Presentación de Fin de Año", tal como fue publicitada.

Los participantes la esperaran con entusiasmo y expectativas un tanto desmedidas en comparación con la realidad de los hechos. Habían creado muchas versiones acerca de dónde sería el debut: el tradicional estadio del Luna Park (el espacio con mayor capacidad de público de la ciudad), el Ministerio de Desarrollo Social, la Legislatura Porteña, el antiguo y clásico Café Tortoni (frecuentado por escritores, músicos, poetas). Pero el único espacio en concreto del que hablaron las terapistas ocupacionales fue el Parador Retiro, que sería reinaugurado a fin de año ${ }^{12}$. La falta de certezas generaba inseguridad, fomentado también porque recién en el último mes del año les habían pedido los talles y pasaban los días y seguían sin entregarles la ropa. Los sentimientos de ansiedad, emoción y la expectativa por el debut del coro, por el mostrarse públicamente compartiendo lo aprendido; se encontraban frente a otros como la bronca por la falta de pago y la inseguridad por la desorganiza-

${ }^{12}$ Este parador estaba siendo refaccionado a raíz de una intervención judicial del lugar, producto de una denuncia realizada por un grupo de beneficiarios ante la Defensoría del Pueblo. Diario Página 12 del 4 de junio de 2008, "Más olvido para los olvidados". 
Salir de la calle: una aproximación etnográfica a un proyecto de revinculación $\quad$ AIS - N. ${ }^{\circ} 30(2011) \quad 173$ social para personas en situación de calle en la Ciudad de Buenos Aires

ción general de la actividad. Pasaba el tiempo y nada parecía concretarse.

\section{El último ensayo del año}

Finalizado el mes de noviembre, los integrantes del coro comenzaron a preguntar con más insistencia por las becas, el debut, las ropas y los planes del proyecto para el 2009. Las terapistas prometían responder al ensayo siguiente, esperando haber obtenido para ese momento alguna información. Cuando sólo un ensayo quedaba para dar respuestas, resolvieron agregar un ensayo más, para esa misma semana. Pero ese día los encontró con las puertas cerradas. El centro cultural donde se realizaban los ensayos no tenía la indicación de reservar ese día el lugar para ellos. Todos quedamos del lado de afuera, junto con los profesores de canto que sin información acerca del aspecto organizativo, no podían hacer más que exteriorizar su indignación: "Para mí esto es una falta de respeto, es inaudito que no venga nadie a poner la cara, una falta de respeto a mi trabajo, a mi tiempo, pero para ellos... para ellos esto es humillante".

Sólo una estudiante de música que colaboraba en la coordinación de la actividad había ido ese día. Ella no entendía que estaba sucediendo. Por teléfono, hablamos con las dos terapistas ocupacionales quienes tampoco sabían qué sucedería con el debut ni con la continuidad del proyecto. Prometieron contactarse en marzo del año siguiente con las personas por medio de los paradores y hogares. "Pero que me están diciendo!" Respondió enojada Graciela, una de las coristas. "No se les ocurre que para marzo del año que viene ya podamos estar en otro lado? No quiero ni pensar que todavía voy a estar en el parador!"

Mientras caía la tarde las personas se fueron reuniendo en pequeños grupos a lo largo y ancho del patio del centro cultural, algunos tomando mate, otros gaseosas, todos alternaban temas triviales en una conversación que cada tanto caía en un tema común relativo al fin de año y a la evaluación de la actividad realizada y abruptamente cerrada. Antes de retirarnos, armamos una cadena de teléfonos y de mails para seguir conectados entre los que estábamos presentes. Los profesores de canto se 
comprometieron a averiguar qué sucedería y manifestaron su voluntad de continuar durante el 2009.

Durante las dos semanas siguientes (las últimas semanas de diciembre de 2008), un grupo autoconvocado siguió reuniéndose en el centro cultural para discutir cómo seguir. Querían que les garantizaran que el proyecto tendría continuidad al año siguiente. Escribieron una carta para presentar en mesa de entradas del GCBA que finalmente no fue entregada. Durante el 2009 no se reiteraron las convocatorias y nadie supo más nada. El proyecto no resurgió, la voluntad de los profesores no alcanzó, y las puertas cerradas de ese último ensayo que no pudo ser, fueron el final abrupto, inesperado, del proyecto del coro. Las ilusiones se diluyeron en el aire.

\section{El fin de la pasiva espera del recurso: la participación y sus logros}

Este proyecto nos muestra entre otras cosas, una experiencia en la que los beneficiarios rompieron con la actitud pasiva de espera del recurso a la cual el Estado los convoca -acorde con modelos clásicos de asistencia directa- empoderándose de un rol no adjudicado como el de "fiscalizadores" del proyecto, monitoreando la ejecución y reclamando la falta de cumplimiento. Como en muchas otras experiencias, la participación aconteció en la etapa de ejecución del proyecto, habiendo estado excluida de la etapa de toma de decisiones, objetivos y del diseño. (Sirvent, 1999). Pero esta vez, la participación fue autoconvocada e interpretada por los técnicos y políticos como un problema imprevisto de la ejecución.

Ellos tomaban la palabra que pretendió ser silenciada. $\mathrm{Ni}$ bien terminado cada ensayo, se acercaban a las coordinadoras de la actividad (las únicas caras visibles de la DGDAl) y les comenzaban a hacer preguntas por cada uno de los problemas de gestión. Al inicio de a uno. La falta de respuestas satisfactorias "caldeaba" el ambiente. La insatisfacción por lo escuchado sumaba más voces, más preguntas. Para hacerse oír, comenzaban a acercarse a las coordinadoras. Este acercamiento corporal, acompañado de las preguntas y quejas simultáneas, daba como resultado un círculo que las rodeaba. No era exagerada la apreciación de ellas, cuando me decían que esperaban que al 
Salir de la calle: una aproximación etnográfica a un proyecto de revinculación $\quad$ AIS - N. ${ }^{\circ} 30(2011) \quad 175$ social para personas en situación de calle en la Ciudad de Buenos Aires

finalizar el ensayo no volvieran a "acosarlas". De manera entendible, las técnicas intentaban de varias maneras evitar este tipo de "asambleas espontáneas" que se había hecho costumbre se desarrollaran al finalizar cada uno de los ensayos. Así lo expresaba Florencia:

"Parece que creen que nosotras somos no sé qué, que podemos hacer algo, no entienden que no depende de nosotras. Que somos sólo las que sostenemos la actividad y ponemos la cara por otros... Al final nos tomaron para que nos hagamos cargo de esto, terminamos siendo las boludas que ponemos la cara por las cagadas que otros se mandan."

No sabremos efectivamente si estas asambleas fueron efectivas o no, pero puedo aseverar que resultaron armas de presión, temas de conversación entre las coordinadoras, los profesores, el coordinador de hogares y paradores, quienes debatían qué hacer frente a estos reclamos. Otras formas de participación fueron la realización de un paro activo en protesta por la falta de pago que interrumpió los ensayos, las discusiones personales y los enfrentamientos colectivos cotidianos. Otros reclamos que no concretaron, pero sí idearon, fueron la planificación de un boicot al debut artístico, la entrega de algunas notas escritas y denuncias colectivas en la Defensoría del Pueblo. $Y$ en cada una de estas instancias, algunas concretadas y otras soñadas, el grupo se consolidaba y el apoyo mutuo y la solidaridad entre ellos crecían. La participación en esta etapa del proyecto no sólo era una necesidad, sino que respondía al derecho a formar parte activa de las decisiones que afectaban a su vida. (Sirvent, 1999).

Algunos logros obtenidos por estos medios, fomentaron la continuidad de la protesta. Las quejas del grupo por la falta de cumplimiento del BAP fueron suficientes para convencer a las terapistas de realizar llamados y quejas obteniendo varias veces una camioneta para ellos. Incluso en una oportunidad, para llevar a una persona con movilidad reducida al hogar donde se alojaba, un grupo de cinco personas reclamó el correspondiente traslado consiguiendo el pago de un taxi. Finalmente, en el mes de diciembre todos los participantes ("nuevos" y "viejos") cobraron la beca retroactiva desde septiembre, siendo esto interpretado como el mayor logro del grupo. En estos ejemplos la 
participación logró una transformación en las formas de convivencia y relación social (Sirvent, 1999) al interior del proyecto.

\section{Palabras finales}

Esta experiencia presentó algunas continuidades y rupturas en comparación con otras políticas sociales dirigidas a personas en situación de calle. Sin duda, las continuidades se dieron en torno a los incumplimientos en lo prometido, las grandes brechas entre lo que el proyecto sería y lo que finalmente pudo ser.

La mayor ruptura la encontramos en la idea de un proyecto para personas en situación de calle que no presupuso la entrega de alimentos ni de alojamiento, recursos a los que el gobierno les da prioridad. En este proyecto el gobierno propuso una actividad, valorada como tarea que ameritaba recibir una contraprestación económica, una actividad creativa, expresiva y llevada a cabo por profesionales de reconocida trayectoria, incluso fuera de las instituciones dedicadas a las personas en situación de calle y fuera del horario de trabajo de esas instituciones.

Una primera lectura de la experiencia me mostró que el proyecto del coro proponía una asistencia desvinculada de la situación de calle, que podría haber sido ofrecida también a otras personas. La propuesta de conformar un coro bajo la dirección del director del coro y del teatro más importante de la Ciudad de Buenos Aires era la mejor propuesta que el gobierno podía ofrecer. Podía ser una alternativa cultural para personas que no estuvieran en situación de calle (las terapistas ocupacionales trabajaron en la identificación de la presencia de la situación de calle en los participantes). Además, la actividad otorgaba la posibilidad de elegir libremente si participar de una propuesta cultural, que se presentaba por fuera del circuito recorrido cotidianamente por personas en situación de calle. Esto constituyó para los participantes una opción y una alternativa a estar en la fila del parador. Indicadores de un proyecto desvinculado de la situación de calle. Sin embargo, atentos a la forma en que el proyecto fue implementado y a las relaciones construidas entre los diferentes actores en él involucrados, esa conclusión dejó de ser absoluta. 
Salir de la calle: una aproximación etnográfica a un proyecto de revinculación $\quad$ AIS - N. ${ }^{\circ} 30(2011) \quad 177$ social para personas en situación de calle en la Ciudad de Buenos Aires

La decisión política de incluir una beca en conceptos de viáticos, y las discusiones que sobre ella sostuvieron las terapistas ocupacionales, nos hablan por un lado, del temor a que las personas no fueran a participar sin una compensación por ello, como si no tuvieran interés para asistir a una propuesta cultural y/o como si no pudieran. Por su parte, el reclamo (legítimo) de las personas en situación de calle en torno al cobro de la beca correspondiente por la tarea realizada, era interpretado como "el único interés" y oscurecía otras motivaciones, así como el hecho de que durante cuatro meses las personas efectivamente fueron a la actividad sin el cobro de la beca.

Por otro lado, las discusiones que las terapistas sostuvieron con algunas personas en situación de calle, en torno a si estaban "realmente" en situación de calle, queriendo identificar "si eran del Bepo o de Retiro", también nos indican que este proyecto formaba parte de una propuesta asistencial que vinculaba a los participantes con esa identidad y con una localización específica: eran "personas en situación de calle residentes de hogares y paradores". Los participantes eran identificados como "de Año Santo" "del Bepo": los espacios que esperaban fueran ocupados por ellos eran la calle misma o algún hogar o parador.

En cuanto a la elección de los participantes, quienes apostaron a que el proyecto continuara y que asistieron a pesar de no contar con la beca ni con la camioneta del BAP, nos indica cierto alejamiento de esas prenociones, resistiendo las ideas asociadas a personas que "son de la calle", que son "del Bepo o de Retiro", mostrando intereses y posibilidades que las personas que "están en la calle", pueden tener y ejercer. En esta experiencia, pudimos conocer algunos de estos intereses y posibilidades que movilizaron a un grupo de más de 30 personas a participar de un proyecto cultural y creativo, vinculado con la expresividad y la emoción, localizado fuera de los márgenes de la ciudad, fuera de los comedores y los albergues.

El proyecto del coro, ideado por fuera del circuito, con profesores e instituciones distintas a las de Desarrollo Social, a los ojos de las terapistas terminó siendo una posta más en el circuito que transitan los beneficiarios. Desilusionadas por la falta de cumplimiento de los objetivos del proyecto, concluyeron que no podría funcionar como un nexo entre la situación de calle marginal y el mercado laboral y cultural. 
Independientemente de que haya podido o no hacerlo, esa expectativa que las terapistas tenían en torno al proyecto -así como la existencia misma de un Área de Revinculación Sociocultural y Laboral- nos indica que las personas en situación de calle eran ubicadas y posicionadas "por fuera" de la sociedad. Si el objetivo era la reinserción social, cultural y laboral, el diagnóstico debía ser la desvinculación, la falta o ausencia de inserción en esos ámbitos. Lejos de ser un espacio vacío, la calle que conocí en mi trabajo de campo, entendida como circuito, contaba con instituciones cotidianamente concurridas, con cierta rutina que favorecía el arraigo a ciertos lugares, preferidos por sobre otros, que fomentaban la generación de vínculos en ellos. Estos aspectos del circuito, en tanto espacio de inserción y de relaciones personales, no se mostraban accesibles a la mirada de las terapistas, convencidas de un dualismo antagónico representado por la sociedad y la calle, como si hubiera un adentro y un afuera, una sociedad con vínculos y relaciones y una calle vacía impersonal, habitada por personas solitarias y aisladas. El haber compartido con los integrantes del coro todos los ensayos, los encuentros previos y algunas salidas posteriores, me permitió conocer las relaciones entabladas entre ellos y con las técnicas. En cada una de estas relaciones, no encontré personas solitarias, sino la presencia de compañerismo, vecindad y en algún caso amistad, que como señalamos en este trabajo, fueron aspectos dimensionados positivamente a la hora de preferir ir al coro, a pesar de no contar con beca, viáticos u otros beneficios. En el mismo sentido, Bachiller (2008) enfatiza la importancia de los vínculos para las personas sin hogar (PSH) en Madrid, donde realizó su investigación. En un debate con el concepto de desafiliación (Castell, 1997) pone en evidencia los límites del discurso que asocia la exclusión con la disolución de sociabilidades, describiendo las relaciones que establecen las PSH en los nuevos territorios de residencia, las redes que establecen en los barrios, las antiguas amistades y vínculos familiares que conservan.

Desde la mirada de las personas en situación de calle que participaron del coro, la expectativa en torno al proyecto era que pudiera permitirles salir de la calle, o como dijo Sergio "salir del parador". Para muchos, salir de la calle era sinónimo a salir del circuito, alejarse del círculo vicioso. La ubicación espacial del 
Salir de la calle: una aproximación etnográfica a un proyecto de revinculación $\quad$ AIS - N. ${ }^{\circ} 30(2011) \quad 179$ social para personas en situación de calle en la Ciudad de Buenos Aires

centro cultural, en una zona turística, la instalación del coro en una institución cultural (y no asistencial) con el prestigio de los profesionales que llevaban adelante el proyecto, indicaban una posición social y espacial fuera del circuito, lo que quedaba más reforzado aún por la promesa de una beca y una salida laboral. Muchos aspectos permitían pensar en la salida. La calle pareciera ser entonces, también para las personas en situación de calle, un lugar al que se llega y del cual se puede salir. El coro iba a ser una puerta a la salida. Ubicado por fuera del circuito, con características que lo diferenciaban de lo conocido, fue entendido y esperado como esa salida.

La participación en esta experiencia nos permitió observar a sus participantes expresando sus intereses, motivaciones y gustos, que lejos de parecer extraños, diferentes o de corresponderse con un "ser ajeno a la sociedad", resultaron bastante similares y conocidos. Además, el coro se constituyó en un espacio cotidiano de demanda y pelea para lograr la obtención de un recurso que les correspondía y que era reclamado como un derecho vulnerado.

Si bien es válido el punto de vista que observa al coro como un punto más del circuito, como un espacio de demanda y de queja por un recurso material que permita sobrevivir, no creo que el proyecto haya sido un "fracaso" como lo interpretaron las técnicas. Vale recordar las notorias diferencias entre el parador y el centro cultural en torno tanto a los vínculos entablados, al acceso a los servicios básicos, como a la diferencia edilicia entre ambos espacios. Además, otras características propias del proyecto del coro y ausente en el circuito, fue la posibilidad de organización colectiva de la protesta (el boicot, el paro activo, las denuncias) defendiendo el espacio del coro, como trabajadores defendiendo su fuente de trabajo. Estas características nos permiten concluir que no, no fue un punto más del circuito. En esta experiencia el placer, la posibilidad de elegir, los gustos, el trato respetuoso y la movilización colectiva y solidaria tuvieron un lugar.

Fueron esas elecciones y el espacio otorgado al placer y al respeto, los que movilizaron a las personas a la defensa del proyecto. A pesar del diseño que dejó por fuera a los saberes de los equipos técnicos y al de las mismas personas involucradas, características de la verticalidad asistencialista de las políticas 
sociales, no se acentuó la indigencia social de no participación (Graciarena, 1983). Al contrario los beneficiarios tomaron en sus manos el "monitoreo" del proyecto, aunque por supuesto sin saberlo. Ellos realizaron el seguimiento de lo pautado con lo ejecutado, señalando qué aspectos de la experiencia debían modificarse y corregirse. Si pudimos encontrar un carácter más democrático en esta política, lo debemos a este hecho de que los beneficiarios hayan intentado constituirse en gestores de ella (Raggio, 1997).

En esta experiencia en particular, el hecho de que la participación no estuviera prevista en el diagnóstico de los problemas, en el diseño y en la ejecución, no impidió que las personas se involucraran haciendo propio el proyecto, y participaran activamente de su seguimiento. Como vimos, hubo grandes diferencias entre tres aspectos: uno fue lo formalmente anunciado, apoyado por la letra escrita de los trípticos utilizados en la difusión del proyecto; otro aspecto tuvo que ver con lo prometido y ofertado en palabras; y finalmente también fue distinto lo efectivamente otorgado. Estas contradicciones entre el dicho y el hecho, entre los compromisos que el GCBA había asumido y lo que finalmente realizó, generaron un clima de tensión importante que se canalizó a partir de variadas manifestaciones, asambleas, paros activos y demás estrategias creativas con las que los usuarios buscaron el cumplimiento de lo prometido y defendieron sus intereses en grupo. Las personas las llevaron a cabo con el objetivo de obtener las contraprestaciones del proyecto que ya era sentido como propio y que deseaban sostener por ser una fuente de goce y placer. Es decir que en el corto plazo, el proyecto tuvo efectos de participación auto-convocada, por supuesto que no previstos en su diseño, y efectos simbólicos y subjetivos de importancia para sus participantes.

\section{Referencias bibliográficas}

BACHILLER, S. (2008). "Exclusión Social, Desafiliación y Usos del Espacio. Una etnografía con Personas Sin Hogar en Madrid". Tesis Doctoral. Facultad de Filosofía y Letras. Universidad Autónoma de Madrid.

CASTEL, R. (1997). La metamorfosis de la cuestión social: Una crónica del salariado. Buenos Aires. Paidos. 
Salir de la calle: una aproximación etnográfica a un proyecto de revinculación $\quad$ AIS - N. ${ }^{\circ} 30(2011) \quad 181$ social para personas en situación de calle en la Ciudad de Buenos Aires

GRACIARENA, J. (1983). "Políticas sociales y de Desarrollo. Alternativas para su integración". En: Desarrollo Social en los ochenta. Santiago de Chile. CEPAL, ILPES, UNICEF.

GRASSI, E.; HINTZE, S. y NEUFELD, M.R. (1994). Políticas sociales, crisis y ajuste estructural. Buenos Aires. Espacio.

MARCHESE, M. (2006). "La construcción del signo 'indigente' en el discurso de las instituciones estatales de la Ciudad de Buenos Aires". En Revista ALED: Asociación Latinoamericana de Estudios del Discurso. Disponible en: http://www. portalaled.com/pt-br/la-construcci\%C3\%B3n-del-signo $\%$ E2\%80\%9Cindigente\%E2\%80\%9D-en-el-discurso-de-lasinstituciones-estatales-de-la-ciudad-de. Recuperado en mayo de 2011.

PANTALEÓN, J. (2004). Entre la Carta y el Formulario. Política y Técnica en el Desarrollo Social. Buenos Aires. Antropofagia.

RAGGIO, L. (1997). "El enfoque antropológico en el estudio de las políticas sociales. Posibilidades y limitaciones". Actas del V Congreso Argentino de Antropología Social. Ciudad de La Plata.

SIRVENT, M.T. (1999). Cultura popular y participación social. Buenos Aires. Miño y Dávila.

\section{Otras fuentes y sitios consultados}

Diario Página 12-4 de junio de 2008: "Más olvido para los olvidados."

www.buenosaires.gov.ar

www.indec.gov.ar

www.medicosdelmundo.org

www.moi.org.ar

www.portalaled.com 